\title{
ILHAS DE CALOR EM IPORÁ-GO: A ANÁLISE DE UM EXPERIMENTO REALIZADO NA PRIMAVERA DE 2015
}

\author{
Mateus Gouveia Alves ${ }^{(\mathrm{a})}$, Sara Oliveira Borges ${ }^{(\mathrm{b})}$, Elvis Santos Neves ${ }^{(\mathrm{c})}$, \\ Bruno Nascimento Duarte ${ }^{(d)}$
}

\footnotetext{
(a) Curso de Geografia, UEG/Campus de Iporá, mateusgolveia.geografia@gmail.com

(b) Curso de Geografia, UEG/Campus de Iporá, soliveira181@gmail.com

(c) Curso de Geografia, UEG/Campus de Iporá, santoselvis07@gmail.com

(d) Curso de Geografia, UEG/Campus de Iporá, brunondcpa@ gmail.com
}

Eixo: Climatologia em diferente níveis escalares: Mudança e variabilidade

\section{Resumo}

\begin{abstract}
A formação de ilhas de calor promove condições de desconforto térmico nas áreas urbanas. Neste sentido, o objetivo deste trabalho consistiu em analisar as características espaciais da ilha de calor urbana na cidade de Iporá-GO por meio de um experimento realizado durante um dia representativo da primavera de 2015. Os dados foram obtidos em cinco pontos da área urbana da cidade por meio de termohigrômetros Data Logger modelo HT-500. Os dados coletados no campo foram organizados em planilhas de cálculo para análise e interpolação. Foi utilizado o software surfer 9.0 para interpolar os dados climáticos e representar, por meio de mapas, a característica espacial da ilha de calor em Iporá. Os resultados revelaram que a maior intensidade da ilha de calor $3,6^{\circ} \mathrm{C}$ foi ocorreu nos horários de $19 \mathrm{~h}$ e $20 \mathrm{~h}$.
\end{abstract}

Palavras chave: Temperatura, Inverno, Clima Urbano

\section{Introdução}

O desconforto térmico atinge grande parte da população que vive nas áreas urbanas, principalmente em bairros com elevada densidade de construção e com ausência de áreas verdes. Nessas áreas a interação entre a radiação solar e superfície é modificada, sendo diferente da interação ocorrida nas áreas rurais. Como resultado dessa modificação ocorre a formação de ilhas de calor.

Segundo Gartland (2010) as Ilhas de calor são formadas em áreas urbanas e suburbanas porque muitos materiais de construção comuns absorvem e retêm mais calor do sol do que materiais naturais em áreas rurais menos urbanizadas.

Amorim (2010) apontou transformações que ocorrem durante o processo de construção e ampliação das cidades que são responsáveis pelas variações de temperatura dentro desse ambiente e consequentemente pela formação de ilhas de calor, são eles: a retirada da vegetação original, o aumento da circulação de veículos e pessoas, a impermeabilização do solo, as mudanças no relevo, por meio de aterros, canalizações de rios e córregos, concentração de edificação verticalização urbana, 
instalação de equipamentos urbanos (parques, praças, edifícios, áreas industriais, residenciais etc.), além do lançamento de partículas e gases poluentes na atmosfera.

Neste sentido o objetivo desta pesquisa consistiu em analisar as características espaciais da ilha de calor urbana na cidade de Iporá-GO por meio de um experimento realizado durante um dia representativo da primavera de 2015. A escolha da primavera se deu em razão de ser neste período que os maiores valores de temperatura do ar são registradas na cidade de Iporá.

\subsection{Caracterização da área de estudo}

Esta pesquisa foi desenvolvida na cidade de Iporá-GO que está inserida na região de planejamento denominada Oeste Goiano, localizada entre as coordenadas geográficas $16^{\circ} 24^{\prime} 00^{\prime \prime}$ e $16^{\circ} 28^{\prime} 00^{\prime \prime} \mathrm{Sul}$, $51^{\circ} 04^{\prime} 00^{\prime}$ e $51^{\circ} 09^{\prime} 00^{\prime \prime}$ Oeste e possui uma população estimada em 32.169 habitantes, conforme o Instituto Brasileiro de Geografia e Estatística - IBGE (2014).

O município de Iporá faz divisa territorial com sete municípios: Amorinópolis e Ivolândia, ao sul, Moiporá e Israelândia, a leste, Diorama e Jaupací, ao norte e Arenópolis a oeste, e está a 220 Km da capital do estado de Goiás (Goiânia).

\section{Procedimentos Metodológicos}

A metodologia utilizada nesta pesquisa foi baseada no sistema de clima urbano - SCU, apresentado por Monteiro (2003), com ênfase no subsistema termodinâmico, no canal de conforto térmico, que aborda as influências do meio natural ou construído no conforto térmico do ser humano. Inicialmente para o desenvolvimento deste trabalho foi realizado o levantamento dos aspectos geoambientais (vegetação urbana, exposição de vertentes, hipsometria e hidrografia) e geourbanos (densidade de construção e pavimentação, uso e ocupação do solo).

Para coleta os dados de temperatura foram utilizados termohigrômetros digitais dataloggers modelo HT-500 acoplados em um mini abrigo de madeira, pintado na cor branca, para proteger da radiação solar. Os mini abrigos foram fixados a 1,5 $\mathrm{m}$ da superfície e os dataloggers foram programados para registrar os valores de temperatura em intervalos de 1 hora e distribuídos em cinco pontos distintos da área urbana de Iporá (tendo como base as características geourbanas e geoambientais).

O experimento foi montado no dia 18 de Outubro de 2015 para analisar se há indícios de ilhas de calor em Iporá no período noturno. Este dia foi escolhido porque se tratava do início da primavera, um período bem quente do ano na cidade de Iporá conforme Alves (2014) e também porque este dia apresentou condições de tempo favorável para analisar indícios de ilhas de calor, pois foi um dia ensolarado sem nuvens e com a ausência de ventos.

O início das coletas dos dados ocorreu entre as $18 \mathrm{~h}$ e $23 \mathrm{~h}$. Os dados obtidos neste intervalo foram organizados em planilhas de cálculo para obter as diferenças térmicas. Posteriormente, foram gerados mapas de temperatura, para cada horário, por meio da ferramenta "New Contour Map" disponibilizada 


\section{OS DESAFIOS DA GEOGRAFIA FÍSICA NA FRONTEIRA DO CONHECIMENTO \\ Instituto de Geociências - Unicamp \\ Campinas - SP \\ 28 de Junho à 02 de Julho de 2017}

no software Srufer 9.0 e identificado em qual região da cidade se formou a ilha de calor e sua evolução entre o intervalo de horários citados.

Também foram utilizadas imagens do satélite Goes 13, das cartas sinóticas da Marinha do Brasil e dos boletins agroclimatológicos do Instituto Nacional de Meteorologia - INMET (2015) para averiguar os sistemas atmosféricos que aturam no dia do experimento.

\section{Resultados}

As seguintes características geoecológicas e geourbanas foram apresentadas em cada ponto de coleta: a) P1 (Campus da UEG): Área urbana, pouco construída, médio índice de vegetação, vertente voltada para oeste, uso de serviços e altitude de 602 m; b) P2 (Secretaria regional de saúde): Área urbana, densamente construída, médio índice de vegetação, vertente voltada para o sul, uso residencial pavimentado e altitude de $576 \mathrm{~m}$;

c) P3 (Vila Itajubá I): Área urbana, densamente construída, baixo índice de vegetação, vertente voltada para noroeste, uso residencial pavimentado e altitude de $620 \mathrm{~m}$; d) P4 (Setor Central): Área urbana, densamente construída, médio índice de vegetação, vertente voltada para oeste, uso comercial, altitude de 602 m; e) P5 (Bairro Mato Grosso): Área urbana, densamente construída, alto índice de vegetação, vertente voltada para sudoeste, uso residencial pavimentado e altitude de $571 \mathrm{~m}$.

Quadro I. Síntese dos aspectos geoecológicos e geourbanos analisados na cidade de Iporá-GO

\begin{tabular}{|c|c|c|c|c|c|}
\hline \multirow{2}{*}{ Pontos } & \multicolumn{3}{|c|}{ Fatores Geoecológicos } & \multicolumn{2}{c|}{ Fatores Geourbanos } \\
\cline { 2 - 6 } & Hips. (m) & $\begin{array}{c}\text { Exp. } \\
\text { Vertente }\end{array}$ & $\begin{array}{c}\text { Vegetação } \\
\text { urbana }\end{array}$ & $\begin{array}{c}\text { Densidade de } \\
\text { construção }\end{array}$ & Uso da terra \\
\hline P1 & 602 & Oeste & $(31-60 \%)$ & $<25 \%$ & Uso de Serviços \\
\hline P2 & 576 & Sul & $(31-60 \%)$ & $76-100 \%$ & Resid. Pavimentado \\
\hline P3 & 620 & Noroeste & $(0-30 \%)$ & $76-100 \%$ & Resid. Pavimentado \\
\hline P4 & 602 & Oeste & $(31-60 \%)$ & $76-100 \%$ & Uso Comercial \\
\hline P5 & 571 & Sudoeste & $(61-90 \%)$ & $76-100 \%$ & Resid. Pavimentado \\
\hline
\end{tabular}

Fonte: Autores (2017)

\subsection{Discussão dos dados climáticos}

Durante o experimento realizado no dia 18 de outubro de 2015 entre as $18 \mathrm{~h}$ e $23 \mathrm{~h}$ o ponto P4 apresentou os maiores valores de temperatura em todos os horários, fazendo com que a ilha de calor se formasse sobre a área deste ponto (Setor Central). (Figura 1). 


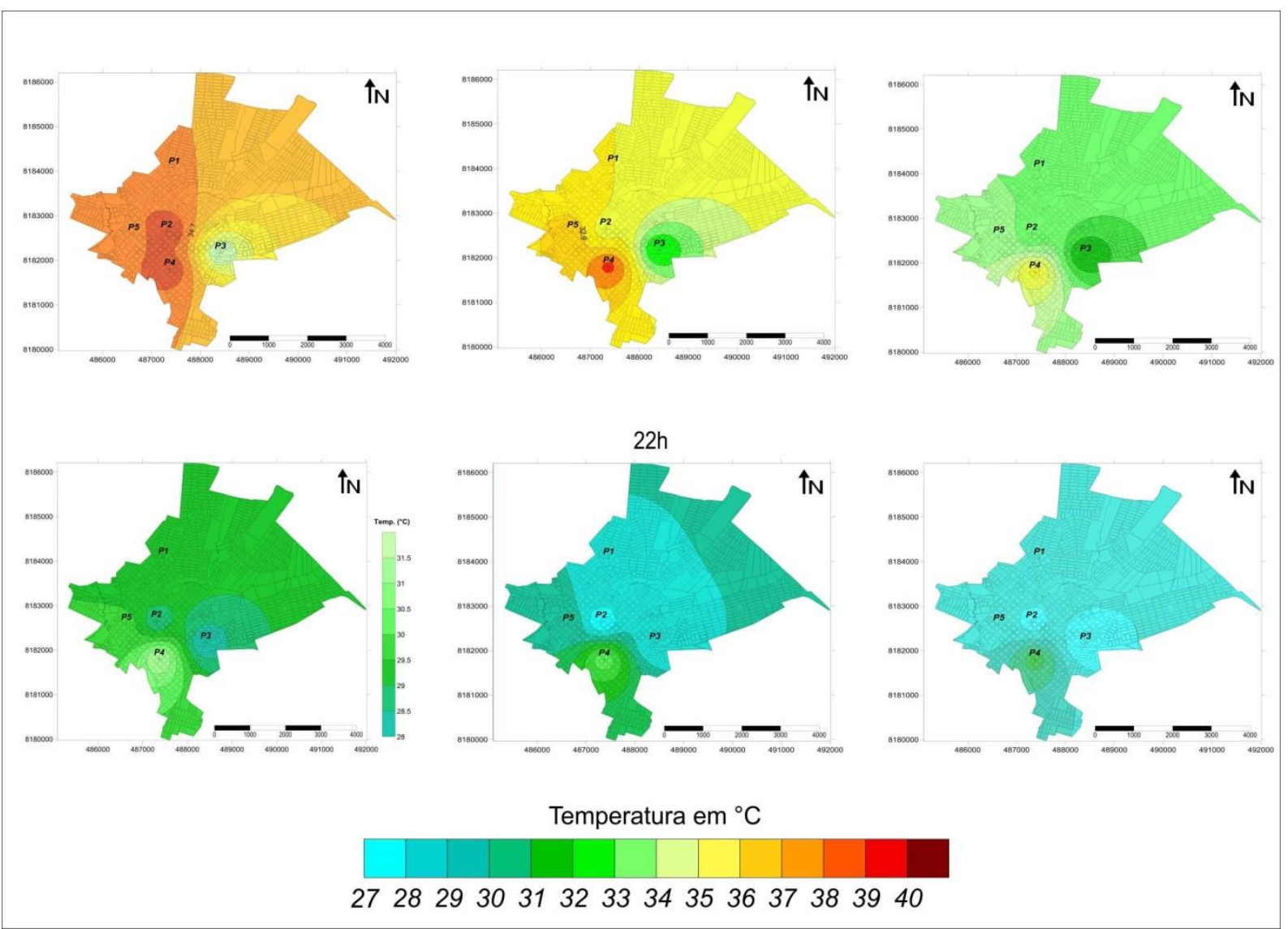

Figura 1 - Padrão espacial da ilha de calor em Iporá-GO no dia 18/10/2015 entre os horários de $18 \mathrm{~h}$ e $23 \mathrm{~h}$ Fonte: Os autores (2017)

A maior intensidade da ilha de calor $3,6^{\circ} \mathrm{C}$ foi registrada durante os horários das $19 \mathrm{~h}$ e $20 \mathrm{~h}$ e a menor intensidade no horário de $23 \mathrm{~h}\left(2,2^{\circ} \mathrm{C}\right)$. Cabe ressaltar que a formação da ilha de calor sobre o $\mathrm{P} 4 \mathrm{em}$ todos os horário ocorreu devido a elevada densidade de construção (entre 76\% e 100\% dos lotes construídos), pavimentação e a pouca vegetação da área. Além desses fatores, durante o dia, na área do P4, há um elevado movimento de pessoas e veículos que contribuem para a geração de calor antropogênico.

Também, por estar em uma vertente voltada para Oeste, durante a tarde a radiação solar atua com maior intensidade nessa área. Somando a isso a alta densidade de construção e a pouca vegetação, essa área da cidade absorve e retém maior quantidade de calor que vai sendo liberado lentamente para a atmosfera com início do período noturno.

\section{Considerações Finais}

Com base no estudo pode-se concluir que o fenômeno ilhas de calor ocorre também em pequenas cidades e não somente nas grandes. Na cidade de Iporá o fenômeno ocorreu exatamente nos pontos onde foi encontrado maior densidade de construção, pavimentação e pouca vegetação. 
Portanto, para minimizar a intensidade das ilhas de calor é necessário implantar mais vegetação nesta área, pois a vegetação impede que os raios solares atinjam diretamente a superfície e promova o aquecimento da mesma.

\section{BIBLIOGRAFIA}

ALVES, W. S.; MARIANO, Z. de F. A distribuição da temperatura e umidade relativa do ar máxima e mínima absoluta: um estudo de caso em Iporá-GO. In: Revista Formação (On-line). Presidente Prudente. 2015. v. 2 n. 22, p. 192 - 211. 2015. Disponível em: http://revista.fct.unesp.br/index.php/formacao/article/view/3846/3085>. Acesso em: 22 abr. 2016.

AMORIM, M. C. C. T. Climatologia e gestão do espaço urbano. Revista Mercator. Fortaleza - CE. 2010, $\quad$ p. $\quad 71 \quad$ - $\quad 90 . \quad$ Disponível em: http://www.mercator.ufc.br/index.php/mercator/article/view/534/299>. Acesso em: 21 maio. 2014 GARTLAND, L. O que é uma ilha de calor. In: GARTLAND, L. Ilhas de calor: como mitigar zonas de calor em áreas urbanas. São Paulo: Oficina de Textos. 2010. p. 09-23.

MONTEIRO, C. A. de F. M. Teoria e clima urbano: Um projeto e seus caminhos. In: MENDONÇA, F. A. Clima urbano. São Paulo: Contexto, 2003. p. 9 - 67. 